\title{
Home Culture Attachment and Iranian Students' Translation Ability
}

\author{
Niloofar Amiri ${ }^{1} \&$ Mandana Yousefi ${ }^{1}$ \\ ${ }^{1}$ Department of English, Quchan Branch, Islamic Azad University, Quchan, Iran \\ Correspondence: Mandana Yousefi, Department of English, Quchan Branch, Islamic Azad University, Quchan, \\ Iran. E-mail: mandanayousefih@gmail.com
}

$\begin{aligned} & \text { Received: August 23, } 2016 \quad \text { Accepted: September 21, } 2016 \quad \text { Online Published: November 23, } 2016 \\ & \text { doi:10.5539/ijel.v6n6p54 }\end{aligned}$ URL: http://dx.doi.org/10.5539/ijel.v6n6p54

\begin{abstract}
English language learning is an important issue whose impact on identity change is remarkable. This study attempted to explore the relationship between Home Culture Attachment (HCA) and Iranian students' translation ability. To this aim, 75 participants were selected and homogenized by administering Oxford Quick Placement Test. To determine the students' HCA levels, they were administered the Home Culture Attachment Scale. Meanwhile, a literary text selected from the book "Dubliners" was used to measure their translation ability. The translations were rated by three raters based on Waddington's Holistic Scale. Finally, Vinay and Darbelnet's Model of Translation was used to determine the applied translation strategies. To analyze the data, Pearson correlation coefficient, multiple regression, independent-sample t-test, and one-way ANOVA were used. The findings indicated that $69.1 \%$ of the students had high HCA and $30.9 \%$ had average HCA. Also, there was a significant correlation between the students' HCA and translation ability. Yet, HCA subscales had no correlation with the translation ability. Moreover, it was found that there was a significant correlation between the students' HCA at the average level and their translation ability and no correlation at the high level. Finally, it was revealed that the most frequent translation strategy was modulation.
\end{abstract}

Keywords: home culture attachment, Vinay and Darbelnet's Model of Translation, Waddington's Holistic Scale

\section{Introduction}

It is well agreed that both language and culture are two inseparable and interrelated entities. In this way, it is suggested that these entities have reciprocated impacts on each other (Pishghadam, Hashemi, \& Bazri, 2013). This is why learning foreign language (FL) can influence learning about another culture and raise interest in a foreign culture, as well. Learning English has resulted in increasing the number of individuals who endeavor to learn it worldwide (Pishghadam \& Zabihi, 2012).

Pishghadam (2011) stated that English language classes noticeably differed from the classes of other subjects of studies at school or university because in such classes the students tend to get familiar with a new culture. Those students learning English-focused subjects tried to adapt themselves with the new culture they encountered. The dialogue between home culture and the foreign culture in class can support the students in shaping new identities. It is then admitted that intercultural contact is a greatly essential feature of learning a new language.

According to Galajda (2011), an English language class plays a pivotal role in forming the identities of its learners as they develop cultural identity as well as a new foreign language identity. Block (2007) also affirms that there are various studies which consistently consider identity as multiple, fluid, and under the influence of social context. However, a second identity in the company of learning a second language and the new culture contact may disorganize the learner's worldview, self-identity, and mindsets, feelings, functioning, and communicating (Brown, 2007). Although, the identity conflict in EFL learning is not as simple as in English as a second language (ESL) learning, such a conflict provides the students with an opportunity to observe their home culture critically (Pishghadam \& Sadeghi, 2011a). While it is suggested by Osler and Starkey (2000) that language learning assists the learners in obtaining a new perception on their own society, the learners are expected to take into consideration diverse facets of their home culture with fresh eyes (Gao, 2008). Moreover, language is claimed to assist the learners to judgmentally discern anything formerly assumed as good or bad, interesting or boring in their society. Indeed, at this instant, learners' diverse historical, social, and cultural backgrounds define the strength of their home culture dependency (Pishghadam \& Sadeghi, 2011b).

The learners might practically appreciate or depreciate their own cultural values following a cultural contact and 
subsequent reflection. Because of this, Pishghadam, Hashemi, and Bazri (2013) asserted that investigating the learners' cultural attachment is significant as this would help us better understand the current situation. There is a rapport between culture and EFL learning through two notions (Nizegorodcew, 2011): One assumes that learning a foreign language weakens the national culture and local values but the other one considers it as an instrument for enhancement of the two cultures. Although the latter is consistent with Bakhtin's (1981) notion of "mutual cultural enrichment" of two cultures in contact, Pishghadam and Navari (2009) claimed that the Iranian context of foreign language learning controverts Bakhtin's notion, indicating that English language teachers and learners in Iran try to greatly pursue the American and British norms. As proposed by Pishghadam and Navari (2009), learners in Iran increasingly underwent a state of losing their home culture by taking distance from their own native culture.

Likewise, Pishghadam and Kamyabi (2009) confirmed that there would be a reduction in students' attachment to their home culture as they adopt more native-like accent, alienating from their own culture. Although Iranian EFL students developed positive attitudes towards the American culture (Pishghadam \& Saboori, 2011), most Polish EFL learners were pleased with living in Poland while exhibiting strong cultural identity (Otwinowska-Kasztelanic, 2011). Nonetheless, language learning helped students achieve a new perspective on their own society (Osler \& Starkey, 2000) and looked at different aspects of their home culture with fresher eyes (Gao, 2008). This is the point where individuals' different historical, social, and cultural backgrounds determine the strength of their home culture dependency (Pishghadam \& Sadeghi, 2011b). EFL teachers and textbooks are influential in determining EFL learners' standpoints on their home culture and language, their understandings of the target culture and language, and their positions on the continuum between the two points (Pishghadam \& Sadeghi, 2011a). Canagarajah (1999) cautioned EFL teachers of enforcing a foreign value system on their learners at the cost of bringing them a common language.

While it is suggested to investigate the relationship between HCA and many other variables such as academic achievement, gender, etc. (Pishghadam \& Sadeghi, 2011b), to the best of the researchers' knowledge, no study has been up to now undertaken dealing with students' translation ability. Owing to the importance of English language learning in Iran and its impact on identity change, investigating the influence of HCA on translation ability can shed more light on the Iranian context of English language learning as well as translation.

Accordingly, there were several purposes for this study. First, it was an attempt to primarily find out the level of HCA among Iranian translation students. Next, the study was aimed at finding out whether there was a significant relationship between student's HCA and translation ability in general. Meanwhile, it was tried to find out whether there was a significant relationship between student's HCA subscales and their translation abilities. Afterward, the research endeavored to determine whether there was a significant difference between students' translation ability with regard their level of HCA. Finally, it was the researchers' concern to discover whether or not the students' HCA affected their translation of the literary text through a qualitative analysis of the data.

\section{Method}

\subsection{Participants}

The sample of this study included all the male and female senior and junior students of translation studying in Binalood, Payam-e-Noor, and Tabaran universities in Mashhad, Iran during the academic year 2014-2015. There was no randomization and intact groups were used for investigation. As for this study, a total number of 75 participants were asked to participate in the study. To homogenize the sample, the Oxford Quick Placement Test (OPT) was distributed among the participants. To this aim, the mean and the standard deviation of the whole group were calculated and only the students who scored from 28- 40, being at the intermediate level (Rezai \& Pakbaz, 2014), were selected. This reduced the total number of the sample to 55 .

\subsection{Instrumentation}

To collect the required data for this study, five instruments were used which are explained as follows:

\subsubsection{Home Culture Attachment Scale (HCAS)}

The scale used in this study for assessing the students' HCA was adopted from Pishghadam, Hashemi, and Bazri (2013). This questionnaire includes 36 items, having a reliability of 0.87 (Pishghadam, Hashemi, \& Bazri, 2013). It $\mathrm{t}$ about 15 minutes for the students to respond the questions which are based on a four-point Likert scale, ranging from (1) "strongly disagree" to (4) "strongly agree". This questionnaire deals with five factors, namely General attachment, Western attachment, Iranian attachment, Cultural attachment, Religious attachment, and Artistic attachment. There are three levels, namely, low, average, and high which are defined according to the obtained score in the questionnaire. In other words, if one participant obtained a score between 1 and 48 , he 
would be placed in the category of low HCA, while a score between 49 and 96 was average, and finally the participant was supposed to have high HCA if he/she scored above 96.

\subsubsection{Oxford Quick Placement Test (OPT)}

In order to homogenize the participants, the OPT (2001) which is a test of English language proficiency developed by Oxford University Press and Cambridge ESOL was administered to the participants. Wistner and Sakai (2008) reports that OPT is reliable and valid as foreign language proficiency tests in EFL settings. OPT includes 60 multiple-choice questions, close comprehension passages, vocabulary, and grammar sections. It takes the participants about 30 minutes to answer the items of the test. The first 40 items are nearly suitable for all the learners and the second part consisting of 20 items are appropriate for more proficient learners.

\subsubsection{Translation Test}

This study aimed to examine the relationship between HCA and literary translations of EFL translation students. To this aim, a literary text selected from the book "Dubliners" by James Joyce was selected as the translation test in order to measure the students' translation ability. This test included 12 sentences ( 240 words) and the students had 30 minutes to translate the sentences from English into Persian. Dubliners is a collection of fifteen short stories first published in 1914. They form a naturalistic depiction of Irish middle class life in and around Dublin in the early years of the 20th century and can have a cultural basis which corresponds to the objectives of this study. The students' translations were rated based on Waddington's holistic scale (2001).

\subsubsection{Waddington's Holistic Scale}

In order to measure the students' translation ability, Waddington (2001) proposes two kinds of methods typically used at European universities, those based on error analysis and those based on a holistic approach. In this study, method C which is a holistic scale was employed (Waddington, 2001). The proposed scale is unitary and treats the translation competence as a whole, but requires the corrector to consider three different aspects of the student's performance. For each of the five levels, there are two possible marks, ending in a score ranging from $0-10$; this allows the corrector freedom to award the higher mark to the candidate who fully meets the requirements of a particular level and the lower mark to the candidate who falls between two levels but is closer to the upper one. In this study, the translations of the senior and junior translation students were holistically rated by three independent raters. To obtain a highly reliable result, the rating scale was fully explained and discussed for the raters during several sessions and the averages of the scores obtained by these raters were regarded as the students' scores on the translation test.

\subsubsection{Vinay and Darbelnet's Model of Translation}

To determine the translation strategies applied by the participants, a collection of 20 translations (out of 55) were randomly selected to be analyzed according to the model proposed by Vinay and Darbelnet's (1995) Model of Translation.

Diverse models of translation have been suggested so far, of which Vinay and Darbelnet's Model of Translation has shown to be more comprehensive helping the raters to better understand the strategies involved in the task of translation (Shahbaiki \& Yousefi, 2013). This model contains two methods encompassing seven procedures listed as follows:

\section{- Direct Translation}

- Borrowing is "a form of direct translation" which involves the transference of the ST word into the TT (Munday, 2009, p. 170). The direct transfer of words like computer, television, mobile, etc. from English to Persian can be considered as some examples of borrowing (Shahbaiki \& Yousefi, 2013).

- Calque: Calque is "a special kind of borrowing whereby a language borrows an expression from another, but then translates literally each of its elements" (Munday, 2009, p. 171). Shahbaiki and Yousefi (2013) proposed the example of translating the word "skyscraper" to "Persian".

- Literal translation: literal translation is "a word-for-word rendering which uses the same number of TL words in the form of established equivalents as well as the same word order and word classes" (Munday, 2009, p. 182).

- Oblique Translation

- Transposition: Transposition "concerns grammatical shift such as word class changes" (Munday, 2009, p. 212).

- Modulation: This includes a "variation of the form of the message, obtained by a change in the point 
of view" (Venuti, 2000, p. 89).

- Equivalence: "Equivalence refers to cases where languages describe the same situation by different stylistic or structural means" (Munday, 2001, p. 58).

- Adaptation: Adaptation is "changing the cultural reference when a situation in the source culture does not exist in the target culture" (Munday, 2001, p. 58).

\subsection{Procedure}

In order to fulfill the purposes of the study, firstly, 75 male and female senior and junior students of translation studying in Binalood, Payam-e-Noor, and Tabaran universities in Mashhad during the academic year 2014-2015 were administered the Oxford Quick Placement Test (OPT). The scores ranging from 28-40, indicating the intermediate level, were selected which reduced the total number of the sample to 55 . Then, the researchers introduced the research objectives and explained how to respond to the questionnaires and do the translations for the participants. Meanwhile, they were assured of confidentiality of the information they provided and their consent were obtained. Then, the translation test, selected from the Dubliners, was administered to all the students to be translated into Persian in 30 minutes. It is worth mentioning that the participants had previously taken the course of literary translation during their education and they were familiar with the requirements of such a translation. Finally, the HCA questionnaire was distributed among the students to determine their HCA levels. Having collected the data, the translation tests were rated by three raters according to Waddington's holistic scale. The final scores of the participants for literary texts were the average of the scores given by these three raters. To answer the research questions, the scores on the translation test and those of HCA questionnaires were statistically analyzed. Furthermore, to find out about the effect of the students' HCA on their translations, some selected translations were qualitatively analyzed according to Vinay and Darbelnet's Model of Translation.

\subsection{Research Design}

In order to determine whether there was a relationship between EFL learners' HCA and their translation ability, a correlational descriptive design was chosen for this study. It included the collection and analysis of quantitative data related to the students' translation ability and their' HCA levels. As for the descriptive phase, the strategies applied by the students for translating the given text were determined.

To address the research objectives, firstly, a Pearson Correlation test was conducted to determine the relationship between translation ability and HCA level. Then, to determine the relationship between the students' HCA subscales and their translation ability, the multiple regression and an ANOVA test were executed. Moreover, an independent-sample t-test was conducted to determine whether there is a significant difference between student's translation ability with regard to their level of HCA. Finally, the applied translation strategies were determined according to Vinay and Darbelnet's Model of Translation.

\subsection{Theoretical Framework}

This study aimed to explore the relationship between HCA and Iranian student's translation ability. The theoretical framework of this study lends its basis to the Sociocultural Theory due to the fact that the variable HCA can be discussed under the framework of this theory. Current conceptualizations of sociocultural theory mostly fall back on the work of Vygotsky (1986), as well as later theoreticians such as Wertsch $(1991,1998)$. As stated by Tharp and Gallimore (1988), the sociocultural perspective brings with itself weighty implications for teaching, schooling, and education. A key feature of this emergent view of human development is that higher order functions develop out of social interaction (Tharp \& Gallimore, 1988).

Vygotsky (1986) debates that a child's development cannot be understood by a study of the individual while it is necessary to examine the external social world in which that individual life has developed. By participating in activities which urge cognitive and communicative functions, children will be attracted to use such functions so that the mentioned functions would nurture and scaffold them. Kublin, Wetherby, Crais, and Prizant (1989) concisely highlight that Vygotsky (1986) pronounced learning as being embedded within social events and occurring as a child interacts with people, objects, and events in the environment. Considering the contributions to sociocultural theory to understanding the development of communication, Adamson \& Chance (1998) argued that there are two particularly noteworthy aspects to a Vygotskian approach to social interactions.

- First, it is fundamentally cultural. Caregivers are agents of culture who set an infant's nascent actions within an intimate setting that is deeply informed by the caregiver's cultural knowledge.

- Second, the notion of a zone of proximal development reveals a pattern of developmental change in which a phase of adult support precedes a phase of independent infant accomplishment. 
Each cycle begins with a newly displayed behavior, such as a smile, a visually directed reach, or babble. The adult's reaction and interpretations transform the infant's emerging behavior into a social act. In essence, the child induces the adult to recruit the act for communication (Kublin et al., 1989). After many experiences of supported expression, the child gradually masters an action that is qualified with cultural meaning. The act has passed through the zone of proximal development during which the adult has educated the child in its use. Sociocultural theory is much more complex but the mentioned aspects are important components to consider when examining the communicative and cognitive development of learners.

\section{Data Analysis and Results}

\subsection{Analysis of Correlation between EFL Students' HCA and Their Translation Ability}

In order to determine the students' HCA, HCAS (Pishghadam, Hashemi, \& Bazri, 2013) was distributed among the participants. The mean of the HCA score for all the participants was 97.58 , that is, the whole sample had an almost high level of HCA. It is of note that the highest HCA score in this sample was 115 while the minimum was 66 . Moreover, most participants $(69.1 \%)$ with a frequency of 38 belonged to the high level and only $30.9 \%$ of the students had average levels of HCA while no one had low levels.

In order to test the first hypothesis "There is no significant relationship between student's HCA and translation ability", since HCA and translation scores were interval scale, it was necessary to primarily determine the normality of students' HCA scores and the translation scores; therefore, One-Sample Kolmogorov-Smirnov Test was conducted whose results are given in Table 1.

Table 1. One-Sample Kolmogorov-Smirnov Test

\begin{tabular}{llll}
\hline & & \multicolumn{1}{c}{ Students' Translation Score } & Students' HCA \\
\hline $\mathbf{N}$ & & 55 & 55 \\
\hline \multirow{2}{*}{ Normal Parameters $^{\mathrm{a}}$} & Mean & 6.00 & 97.58 \\
& $\mathrm{SD}$ & 1.036 & 8.892 \\
\hline \multirow{2}{*}{ Most Extreme Differences } & Absolute & .227 & .165 \\
& Positive & .227 & .126 \\
& Negative & -.209 & -.165 \\
\hline Kolmogorov-Smirnov Z & & 1.685 & 1.222 \\
\hline Asymp. Sig. (2-tailed) & & .671 & .101 \\
\hline
\end{tabular}

Note. ${ }^{\text {a. }}$ Test distribution is Normal.

As it can be observed, the p-value of the One-Sample Kolmogorov-Smirnov Test was 0.101 for the students' HCA score which is larger than 0.05 indicating that the assumption for normality of the data distribution for this group is not rejected. In other words, it can be concluded that the distribution of the scores for the students' HCA was normal. Likewise, the p-value of the One-Sample Kolmogorov-Smirnov Test was 0.671 for the students' translation scores which is larger than 0.05 showing that the assumption for normality of the data distribution for this group is not also rejected concluding that the distribution of the scores for the students' proficiency was normal. Having taken into considerations the normality of the abovementioned variables, a Pearson correlation test was conducted for identifying the relationship between them. The results of this analysis are displayed in Table 2 .

Table 2. Pearson correlation test for HCA and translation ability

\begin{tabular}{|c|c|c|c|c|}
\hline & & $\begin{array}{l}\text { Students' } \\
\text { ability }\end{array}$ & Translation & Students' HCA \\
\hline \multirow{3}{*}{$\begin{array}{l}\text { Students' } \\
\text { ability }\end{array}$} & Pearson Correlation & 1 & & $-.293^{*}$ \\
\hline & Sig. (2-tailed) & & & .030 \\
\hline & $\mathrm{N}$ & 55 & & 55 \\
\hline \multirow{3}{*}{ Students' HCA } & Pearson Correlation & $-.293^{*}$ & & 1 \\
\hline & Sig. (2-tailed) & .030 & & \\
\hline & $\mathrm{N}$ & 55 & & 55 \\
\hline
\end{tabular}

Note. * Correlation is significant at the 0.05 level (2-tailed). 
The Table shows that the obtained p-value of the Pearson correlation test is 0.03 which is less than 0.05 . Therefore, it is concluded that there was a significant correlation between the students' HCA and translation ability.

\subsection{Correlation between EFL Students' HCA Subscales and Their Translation Ability}

In order to examine the relationship between the subscales of HCA and the learners' translation ability, a multiple regression was conducted. In fact, multiple regression is used to formulate the equation of the Least Squares Regression Line, the 'best fit' line of predicted values and to get Pearson's "r" Statistic, which is a statistic that demonstrates the strength, direction, and significance of the linear relationship between variables (Creswell, 2009). Table 3 indicates the results of this analysis. The Sig. values were 0.176 for Religious attachment, 0.056 for the western attachment, 0.329 for Iranian attachment, 0.197 for cultural attachment, and finally 0.204 for artistic attachment.

Table 3. Multiple regression for correlation between HCA subscales and translation scores

\begin{tabular}{llllllll}
\hline & & Translation Score & Religious & western & Iranian & cultural & artistic \\
\hline Pearson Correlation & Translation Score & 1.000 & -.128 & -.217 & -.061 & -.117 & -.114 \\
& Religious & -.128 & 1.000 & -.338 & .472 & .459 & -.224 \\
& western & -.217 & -.338 & 1.000 & -.239 & -.277 & .489 \\
& Iranian & -.061 & .472 & -.239 & 1.000 & .678 & -.302 \\
& cultural & -.117 & .459 & -.277 & .678 & 1.000 & -.247 \\
& artistic & -.114 & -.224 & .489 & -.302 & -.247 & 1.000 \\
\hline Sig. & Translation Score &. & .176 & .056 & .329 & .197 & .204 \\
& Religious & .176 &. & .006 & .000 & .000 & .050 \\
& western & .056 & .006 &. & .039 & .020 & .000 \\
& Iranian & .329 & .000 & .039 &. & .000 & .012 \\
& cultural & .197 & .000 & .020 & .000 &. & .035 \\
& artistic & .204 & .050 & .000 & .012 & .035 &. \\
\hline $\mathrm{N}$ & Translation Score & 55 & 55 & 55 & 55 & 55 & 55 \\
& Religious & 55 & 55 & 55 & 55 & 55 & 55 \\
& western & 55 & 55 & 55 & 55 & 55 & 55 \\
& Iranian & 55 & 55 & 55 & 55 & 55 & 55 \\
& cultural & 55 & 55 & 55 & 55 & 55 & 55 \\
& artistic & 55 & 55 & 55 & 55 & 55 & 55 \\
\hline
\end{tabular}

Following this, an ANOVA test was also run to examine the strength of the results. As shown in Table 4, the p-value of ANOVA test is 0.335 which is larger than 0.05 . This implies that the assumption of equality of means for translations scores between various subscales of HCA is not rejected and translations scores are not significantly related with the HCA subscales. In other words, it can be claimed that HCA subscales are not a predictor of translation ability.

Table 4. ANOVA analysis concerning HCA subscales and translation scores

\begin{tabular}{lllllll}
\hline Model & & Sum of Squares & df & Mean Square & F & Sig. \\
\hline 1 & Regression & 6.214 & 5 & 1.243 & 1.176 & $.335^{\text {a }}$ \\
& Residual & 51.786 & 49 & 1.057 & & \\
& Total & 58.000 & 54 & & & \\
\hline
\end{tabular}

Note. ${ }^{\text {a }}$ Predictors: (Constant), artistic, Religious, cultural, western, Iranian attachments. 


\subsection{Independent-sample T-test with Regard to HCA Levels and Translation Ability}

Having found out that there was a significant relationship between HCA and students' translation ability, a paired-sample t-test was conducted to determine whether there is a significant difference between the students with different levels of HCA (average and high) with regard to their translation ability or not. Prior to conducting the t-test, it is required to determine the normality of students' HCA scores in average and high levels; thus, a One-Sample Kolmogorov-Smirnov Test was employed and it was observed that the p-value was respectively 0.568 and 0.177 for the students with average and high levels of HCA which were larger than 0.05 demonstrating that the assumption for normality of the data distribution for both groups are not rejected. In other words, it could be concluded that the distribution of the scores for the students with average and high HCA was normal. Then, a Levene's test was run to investigate the assumption of equality of variances in the mentioned levels. It was observed that the p-value of the Levene's test was 0.014 (Table 5) which was less than 0.05 , and accordingly, the assumption of equality of variances for these two groups was not rejected. This implied that the variance of these two groups was equal for both average and high levels.

Table 5. Levene's test for equality of variances for the average and high HCA

\begin{tabular}{llll}
\hline & & \multicolumn{2}{l}{ Levene's test for Equality of variances } \\
\hline \multirow{3}{*}{ HCA } & Equal variance assumed & F & Sig. \\
\cline { 2 - 4 } & Equal variance not assumed & 6.413 & .014 \\
\hline
\end{tabular}

Having tested the above-mentioned hypotheses, the Independent-sample t-test was conducted. .As Table 6 indicates, it can be observed that the p-value for this test was 0.00 (lower than 0.05 ), therefore, the assumption of mean equality for two levels of HCA, considering the equality of variances, was rejected. In other words, it can be claimed that there was a significant difference between the students with high and average HCA with regard to their translation ability.

Table 6. Independent-sample t-test for students' HCA at two average and high levels

\begin{tabular}{lllllllll}
\hline & \multicolumn{1}{c}{$\mathrm{t}$-test for Equality of Means } & & & \\
\cline { 3 - 8 } & $\mathrm{t}$ & $\mathrm{df}$ & $\begin{array}{l}\text { Sig. } \\
(2 \text {-tailed })\end{array}$ & $\begin{array}{l}\text { Mean } \\
\text { Difference }\end{array}$ & $\begin{array}{l}\text { Std. Error } \\
\text { Difference }\end{array}$ & $\begin{array}{l}\text { 95\% Confidence Interval } \\
\text { of the Difference }\end{array}$ \\
\hline \multirow{3}{*}{$\mathrm{HCA}$} & $\begin{array}{l}\text { Equal variances } \\
\text { assumed }\end{array}$ & -7.923 & 53 & .000 & -14.039 & 1.772 & -17.593 & -10.485 \\
\cline { 2 - 8 } & $\begin{array}{l}\text { Equal variances not } \\
\text { assumed }\end{array}$ & -6.603 & 21.452 & .000 & -14.039 & 2.126 & -18.455 & -9.623 \\
\hline
\end{tabular}

As far as the fourth research question is concerned, it was tried to find out whether there is a significant correlation between the students' HCA at the average and high levels and their translation ability, thus, Pearson correlation tests were conducted after determining the normality which was established. The results indicated that the obtained p-value at the average level was 0.018 which was lower than 0.05 and this implies that there was a significant correlation between the students' HCA at the average level and their literary translation ability. However, the obtained p-value at the high level was 0.44 which was larger than 0.05 ., and thus it can be concluded that there was no significant correlation between the students' HCA at the high level and their literary translation ability. The following Tables show the results:

Table 7. Pearson correlation test for translation and HCA at the average level

\begin{tabular}{llll}
\hline translation scores & Pearson Correlation & 1 & $-.566^{*}$ \\
\cline { 2 - 4 } & Sig. (2-tailed) & 17 & .018 \\
& $\mathrm{~N}$ & 17 & 17 \\
\hline Average HCA & Pearson Correlation & $-.566^{*}$ & 1 \\
& Sig. (2-tailed) & .018 & \\
$\mathrm{~N}$ & 17 & 17 \\
\hline
\end{tabular}

Note. $*$ Correlation is significant at the 0.05 level (2-tailed). 
Table 8. Pearson correlation test for translation and HCA at the high level

\begin{tabular}{llll}
\hline Translation score & Pearson Correlation & 1 & .129 \\
& Sig. (2-tailed) & & .440 \\
& $\mathrm{~N}$ & 38 & 38 \\
\hline high levels of HCA & Pearson Correlation & .129 & 1 \\
& Sig. (2-tailed) & .440 & \\
& $\mathrm{~N}$ & 38 & 38 \\
\hline
\end{tabular}

\subsection{Applied Translation Strategies based on Vinay and Darbelnet's Model}

A random collection of 20 translations were analyzed qualitatively to determine the applied strategies based on the proposed criterion by Vinay and Darbelnet's Model of Translation. As it can be seen in Figure 1, the most frequent strategy used by the students with high HCA was modulation with a frequency of 181 cases $(74.8 \%)$. Adaptation and Literal translation were both the same with a frequency of 15 cases (6.2\%). Then, calque with 14 cases $(5.8 \%)$ and Transposition with 10 cases $(4.1 \%)$ and borrowing with only 7 cases $(2.9 \%)$ were the least frequent ones. It is of note that equivalence was never used by any of the participants.

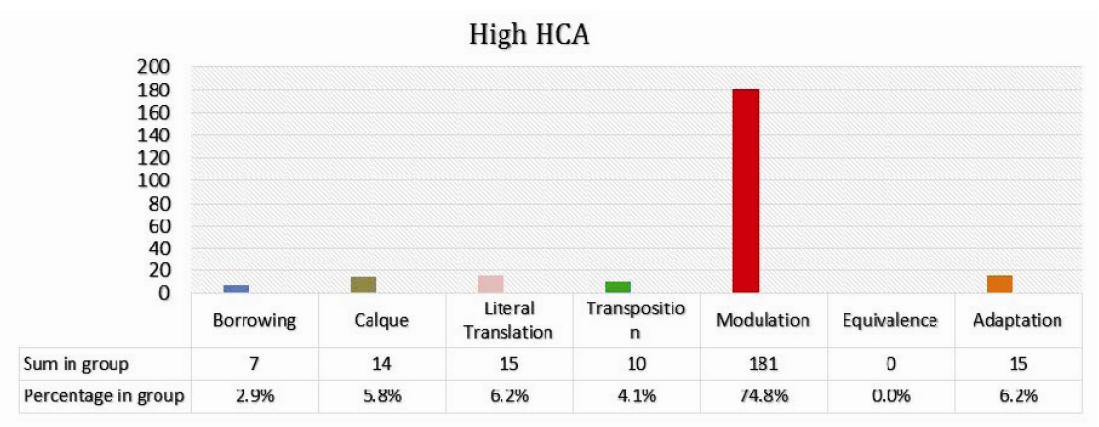

Figure 1. Applied translation strategies by students with high HCA

Figure 2 exhibits that the most frequent strategies used by students with average HCA was modulation with a frequency of 168 cases $(70.9 \%)$. Transposition was the next frequent strategy with 18 cases $(7.6 \%)$. Then, adaptation and Literal translation with a frequency of 17 cases $(7.2 \%)$, calque with 9 cases $(3.8 \%)$, and borrowing with 8 cases (3.4\%) were the least frequent ones. Again, equivalence was never used by any of the participants.

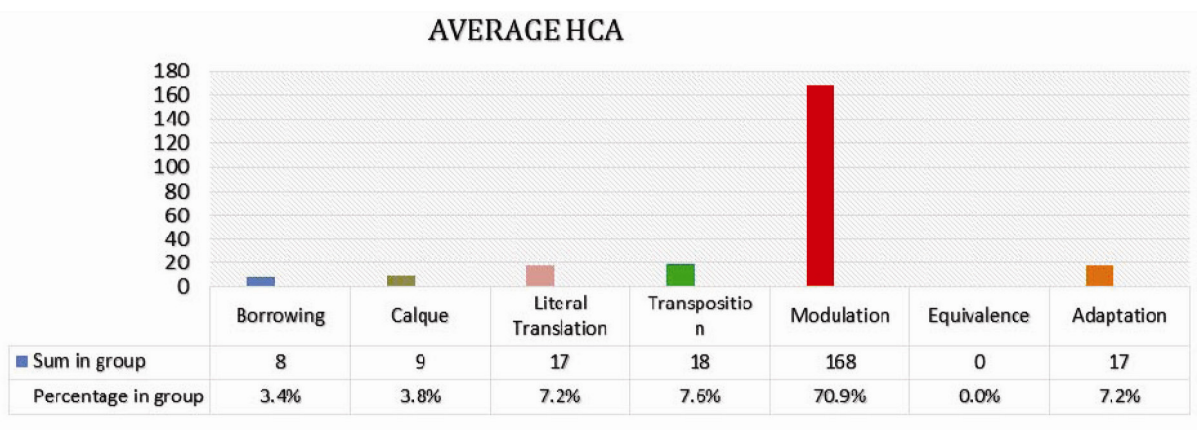

Figure 2. Applied translation strategies by students with average HCA 
In sum, it can be seen that the most frequent strategy used by both groups was modulation with a frequency of 349 cases $(72.9 \%)$ and the least frequent one was borrowing with only 15 cases (3.1\%).

As with regard to the last research question, that is, whether there is any significant difference between the students with high and average HCA with regard to the applied translation strategies, a Chi-square statistical test was conducted. The total number of the strategies being used by the students with high HCA level was 242 , while it was 237 for the students with average HCA. Table 9 indicates the results of this analysis:

Table 9. Chi-Square tests

\begin{tabular}{llll}
\hline & Value & df & Asymp. Sig. (2-sided) \\
\hline Pearson Chi-Square & $9.667^{\mathrm{a}}$ & 9 & .378 \\
Likelihood Ratio & 12.816 & 9 & .171 \\
Linear-by-Linear Association & .060 & 1 & .806 \\
$\mathbf{N}$ of Valid Cases & 20 & & \\
\hline
\end{tabular}

Note. 20 cells (100.0\%) have been expected to count less than 5 . The minimum expected count is .50 .

As the sig value which is larger than 0.05 shows, there is no significant difference between the strategies used by students with high and average HCA.

\section{Discussion and Conclusion}

In this study, the main objective was to examine the relationship between EFL learners' HCA and their translation ability. Considering the HCA levels, namely, low, average, and high, it was observed that most students $(69.1 \%$ ) belonged to the high level while only $30.9 \%$ of the students had average levels of HCA and no one belonged to low. Then, a Pearson correlation test was used for identifying the relationship between the two variables and it was concluded that there was a significant correlation between the students' HCA and their translation ability. In fact, Pishghadam and Sadeghi (2011b) reported that literacy had no significant relationship with HCA while they deeply investigated the role of EFL teachers' access to social and cultural capital in their HCA. As for this finding, Pishghadam and Sadeghi (2011b) explained that this result happened because the scale they used for data collection only valued the amount of information accumulated by the individual's reinforced habit of reading books through years following the motto that each book is worth reading once, no matter whether the information gathered is potentially supporting or threatening their home culture as if the materials read are from abstractly scientific textbooks free from any cultural orientation.

In another study by Lee (2002), the role of cultural identity and heritage language maintenance among the lives of 40 second-generation Korean-American university students in the United States was examined. Their findings indicated that most second-generation Korean-Americans achieve some level of Korean proficiency, but they overwhelmingly agree that it is not enough. They acknowledged the importance of knowing their heritage language, but felt that the existing language courses in the community-based language schools are not meeting their needs. The participants agreed that the absence of societal recognition of the importance in maintaining their heritage language was the most significant factor in their lack of motivation to maintain their heritage language. Furthermore, it was found that heritage language proficiency was related to strength of bicultural identification. As for our study, it seems translation ability, despite of its level, is correlated with HCA and running further research to understand the factors, apart from translation ability, which affect the students' HCA is required.

The third purpose of this study was to examine the relationship between EFL students' HCA subscales and their translation ability. The results indicated that HCA subscales are not a predictor of translation ability. Consistent with that of Hejazi, Ghonsooly, Pishghadam, and Ahmadi (2015), this study concluded that if the learner's home culture is consistent with the target culture, the process of language learning accelerates. Nonetheless, if there is a distance between different aspects of Home and target cultures, there will be little flexibility in accepting the target culture by the learners. Hejazi et al. (2015) declare that such a fact will consequently hinder or retard the process of second language learning. The results of this study, yet, showed that significant correlation existed between the students' HCA and translation ability, i.e. the more the HCA, the better the translation performance.

It is declared by many researchers that the cultural background of a reader influences his or her ability in understanding texts (Anderson, Sapiro, \& Montague, 1977; Barnet, 1989; Carrell, 1987; Steffensen, Joag-Dev, \& Anderson, 1979). This immersion allows them interpret the concepts in the TL because the learners are 
embedded in the cultural context of their own home society (Kourova \& Modianos, 2013). In line with this, it is claimed that self-culture awareness is a basis for comparing and contrasting the two cultures. Such a thing can facilitate learning the foreign language resulting in the development of their competence with target culture (Kun, 2013; Kramsch, 1993). After the learners have developed their competence with the target culture and language, they make the judgment either to accept or not accept the target cultural concepts. These findings to some degree explain the existence of a relationship between Iranian HCA and their translation ability.

The other purpose in this study was to explore whether there was a difference between EFL students' literary translation ability with regard to their level of HCA. The findings indicated that the participants did not exhibit low levels of HCA and there was a significant difference between the translation students' HCA at average and high level. However, there was a significant correlation between the students' HCA at the average level and their translation ability while no significant correlation was observed at the high level.

Finally, it was found that the most frequent strategy used by the students with high and average HCA was modulation and the least frequent strategy namely borrowing. As for this finding, there are many contradictory results in the literature. For example, Yarahmadzehi, Beikian, and Nadri (2013) investigated using English phrasal verbs by Persian translation theorists and translators. In their study, three of the Persian translations of the novel 'Harry Potter and the Order of the Phoenix' by Rowling were examined along the original text on the basis of Newmark (1988) and Vinay and Darblenet's (1995) taxonomies of translation procedures. They reported that equivalence was the most frequent strategy while in our study it was never used because of the sentences in the translation test. Equivalence refers to a strategy to describe the same situation by "using completely different stylistic or structural methods" for producing "equivalent texts". Equivalence is not only useful but also necessary in translating idioms and proverbs. This strategy is viewed as a type of modulation and "a linguistic sub-discipline of pragmatics" (Armstrong, 2005, p.152), which is concerned with the use of language in different cultures. The change in stylistics is another kind of application to equivalence. Language used in one style often has a contrary meaning against what seems to be its literal meaning. In the translation test being distributed among the participants in this study, there was no idiom or phrasal verb, and thus, using no equivalence was not a wonder.

In another study, Pahlavani, Bateni, and Shams Hosseini (2014) scrutinized the collocations in translation of literary texts and revealed that the translators selected diverse strategies such as Literal Translation 35.73\%, Equivalence 30.93\%, Total Omission 20.8\%, Mistranslated Items 3.14\%, Partial Omission 2.4\%, Calque 2.94\%, Transposition $2.13 \%$, Modulation $1.4 \%$, and Transliteration $0.53 \%$. Yet, Adaptation had no place in translation of collocations from English into Persian in the novels. In their study, literal translation was the most frequent strategy while the second top strategy was equivalence.

Meanwhile, Shahbaiki, and Yousefi (2013) scrutinized the translation of Adjective-Noun collocations from English into Persian. Their findings revealed that employed procedures in both translations included equivalence, literal translation, modulation, and transposition.

Lotfollahi, Ketabi, \& Barati (2013) also investigated Persian translation of English print advertisements for cosmetic and hygienic products. They employed Vinay and Darbelnet's (1995) approach and revealed that the main translation procedures used were literal and borrowing. This finding is in contrast with the results of our study which indicated that borrowing was at a low rate and this can be attributed to the type of the text given to the subjects. This diversity in the type of strategies being used can be also attributed to the contexts of the studies, the genres being scrutinized, and the texts being translated. Dohaei and Ketabi (2015) claimed that the semantic aspects of language are important in translations. Semantic aspects of language are other types of linguistic elements which participants have problem with understanding them. For example, the word "lovely coffee" denotes collocation. Moreover, the word 'in your cup' is Methapor'. Since students are not conceptually fluent, the meaning obtained from the semantic aspects of language became indirect and cause hinder in production of student's knowledge. Hashemian \& Talebinejad (2007) also declare that L2 learners do not have access to conceptual system of English. That is why their written discourse showed a high degree of literariness. It seems that HCA does not exert any special effects on the students' use of translation strategies, and this might be attributed to other variables such as their awareness and knowledge of such strategies, proficiency, experience, etc.

According to Pishghadam and Kamyabi (2009), there will be a reduction in students' attachment to their home culture as they adopt more native-like accent, alienating from their own culture. Therefore, the results of this study are important because it brings awareness for EFL translation students and teachers, as well as syllabus designers about the fact that cultural dimension of language learning can be a principal aspect while translating 
texts from other cultures into the home culture. Considering HCA, it was found that the students mostly possessed high levels. It seems necessary to promote and strengthen the HCA among students of all disciplines as it may foster achievement in some ways. Pishghadam and Navari (2009) indicated that in Iran English language learners try hard to follow the American and British norms and progressively endure a state of losing home culture that is taking distance from ones' own native culture by exposure to the English culture. Then this might be taken for serious that fostering the HCA levels among the learners should not end up at the cost of losing one's own culture.

It was found in this study that the translation students belonged to level 3 of the Waddington' (2001) scale meaning that they had an adequate knowledge to transfer the general idea(s) but with a number of lapses in accuracy. With regard to this, policy makers and educationalists are encouraged to promote the students' overall abilities to upper levels. It seems the students do not have a noticeable proficiency level, nor are they familiar with the translation techniques and practices. If the translation curriculum targets at enhancing the students' knowledge, better renderings will be expected accordingly. In other words, in any instructional setting, learners' negotiations with others and with different cultural variables (HCA) are crucial to the development of rich and powerful language learning and use.

\section{References}

Adamson, L. B., \& Chance, S. E. (1998). Coordinating attention to people, objects, and language. In A. M. Wetherby, S. F. Warren, \& J. Reichle (Eds.), Transitions in prelinguistic communication (pp. 15-38). Baltimore, MD: Paul H. Brookes.

Anderson, R., Sapiro, R., \& Montague, W. (Eds.) (1977). Schooling and the acquisition of knowledge. Hillsdale, NJ: Lawrence Erlbaum Assocs.

Armstrong, N. (2005). Translation, linguistics, culture: A French-English handbook, 27. Multilingual matters.

Barnett, M. (1989). Teaching Reading Strategies: How Methodology Affects Course Articulation. Foreign Language Annals, 21, 109-121. http://dx.doi.org/10.1111/j.1944-9720.1988.tb03119.x

Block, D. (2007). Second language identities. New York, NY: Continuum.

Brown, H. D. (2007). Principles of language learning and teaching (5th ed.). NY: Pearson Education, Inc.

Canagarajah, A. S. (1999). Resisting linguistic imperialism in English teaching. Oxford: Oxford University Press.

Carrell, P. L. (1987). Content and formal schemata in ESL reading. TESOL Quaterly, 21(3), 461-481. http://dx.doi.org/10.2307/3586498

Creswell, J. (2009). Research Design; Qualitative and Quantitative and Mixed Methods Approaches. London: Sage Publication.

Dohaei, M., \& Ketabi, S. (2015). A discourse analysis of coffee and chocolate print advertisements: Persian EFL learner's problems in focus. Mediterranean Journal of Social Sciences, 6(3 S1), 220-230. http://dx.doi.org/10.5901/mjss.2015.v6n3s1p220

Galajda, D. (2011). The contribution of FL learning experiences to the development of multicultural identity. In J. Arabski \& A. Wojtaszek (Eds.), Aspects of culture in second language acquisition and foreign language learning (pp. 49-62). New York: Springer. http://dx.doi.org/10.1007/978-3-642-20201-8_5

Gao, Y. H. (2008). English learning and identity construction in the Chinese EFL context. In Pac SLRF 2008 \& the third national symposium on SLA. Symposium conducted at the 6th meeting of the Pacific Second Language Research Forum (Pac SLRF), Beijing.

Hashemian, M., \& Talebinejad, M. R. (2007).The development of conceptual fluency and methaporical competence in L2 learning. Linguistik online, 30(1). Retrieved from www.linguistik-online.com/30_07/hashemianNezhad.html

Hejazi, M., Ghonsooly, B., Pishghadam, R., \& Ahmadi, H. S. (2015). Home Culture Attachment and Comprehending L2 Written Texts: A Study on EFL learners in Iran. Mediterranean Journal of Social Sciences, 6(4), 383-390. http://dx.doi.org/10.5901/mjss.2015.v6n4s3p383

Kourova, A., \& Modianos, D. (2013). Inter-cultural awareness and its role in enriching students' communicative competence. The International HETL Review, Special issue, 60-70.

Kramsch, C. (1993). Context and culture in language teaching. Oxford: Oxford University Press. 
Kublin, K. S., Wetherby, A. M., Crais, E. R., \& Prizant, B. M. (1989). Prelinguistic dynamic assessment: A transactional perspective. In A. M. Wetherby, S. F. Warren, \& J. Reichle (Eds.), Transitions in prelinguistic communication (pp. 285-312). Baltimore, MD: Paul H. Brookes.

Kun, L. (2013). The culture study in foreign language education. International Review of Social Sciences and Humanities, 6(1), 196-204.

Lee, J. S. (2002) The Korean language in America: the role of cultural identity in heritage language learning. Language, Culture and Curriculum, 15(2). 117-133. http://dx.doi.org/10.1080/07908310208666638

Lotfollahi, B., Ketabi, S., \& Barati, H. (2013). Persian Translation of English Print Advertisements for Cosmetic and Hygienic Products. The Iranian EFL Journal, 9(3), 320-331.

Munday, J. (2001). Introducing translation studies: theories and application. London and New York: Routledge.

Munday, J. (2009). The Routledge companion to translation studies. London: Routledge.

Newmark, P. (1988). A textbook of translation, 1. New York: Prentice hall.

Nizegorodcew, A. (2011). Understanding culture through a lingua Franca. In J. Arabski \& A. Wojtaszek (Eds.), Aspects of culture in second language acquisition and foreign language learning (pp. 7-20). New York, NY: Springer. http://dx.doi.org/10.1007/978-3-642-20201-8_4

Osler, A., \& Starkey, H. (2000). Intercultural education and foreign language learning: Issues of racism, identity and modernity [Abstract]. Race Ethnicity and Education, 3(2), 207-221.

Otwinowska-Kasztelanic, A. (2011). Do we need to teach culture and how much culture do we need? In J. Arabski \& A. Wojtaszek (Eds.), Aspects of culture in second language acquisition and foreign language learning (pp. 35-48). New York, NY: Springer.

Pahlavani, S. D., Bateni, B., \& Shams Hosseini, H. (2014).Translatability and Untranslatability of Collocations in Ernest Hemingway's Novels. European Online Journal of Natural and Social Sciences, 3(4), 1195-1206.

Pishghadam, R. (2011). Introducing applied ELT as a new approach in second/foreign language studies. Iranian EFL Journal, 7(2), 9-20.

Pishghadam, R., \& Kamyabi, A. (2009). The Relationship between accent and deculturation among EFL learners in Iran. Paper presented at 7th international TELSSI conference, Yazd, Iran.

Pishghadam, R., \& Navari, S. (2009). Cultural literacy in language learning: Enrichment or derichment. Paper presented at 1st International Conference on Languages, Malaysia.

Pishghadam, R., \& Saboori, F. (2011). A qualitative analysis of ELT in the language institutes of Iran in the light of the theory of "World Englishes". Journal of Language Teaching and Research, 2(3), 569-579. http://dx.doi.org/10.4304/jltr.2.3.569-579

Pishghadam, R., \& Sadeghi, M. (2011a). Culture and identity change among Iranian EFL teachers. Ozean Journal of Social Sciences, 4(3), 147-162.

Pishghadam, R., \& Sadeghi, M. (2011b). Home culture attachment and access to social/cultural capital: A case of Iranian foreign language teachers. African Journal of Social Sciences, 1(3), 56-65.

Pishghadam, R., \& Zabihi, R. (2012). Life syllabus: A new research agenda in English language teaching. TESOL Arabia Perspectives, 19(1), 23-27.

Pishghadam, R., Hashemi, M. R., \& Bazri, E. (2013).Specifying the underlying constructs of the Home Culture Attachment Scale. Iranian Journal of Society, Culture \& Language, 1(1), 37-51.

Rezai, M. J., \& Pakbaz, R. (2014). Iranian EFL Learners' Processing of English Derived Words. Issues in Language Teaching, 3(1), 37-64.

Shahbaiki, A., \&Yousefi, M. (2013). A comparative study of adjective-noun collocations from English into Persian in Jane Eyre by Charlotte Bronte. International Journal of Language Learning and Applied Linguistics World, 4(3), 13-23.

Steffensen, M. S., Joag-Dev, C., \& Anderson, R. C. (1979). A cross-cultural perspective on reading comprehension. Reading Research Quarterly, 15(1), 10-29. http://dx.doi.org/10.2307/747429

Tharp, R. G., \& Gallimore, R. (1988). Rousing minds to life: Teaching, learning, and schooling in social context. Cambridge: Cambridge University Press.

Venuti, L. (2000). The translation studies reader. London: Routledge. http://dx.doi.org/10.4324/9780203446621 
Vinay, J. P., \& Darbelnet, J. (1995). Comparative stylistics of French and English: a methodology for translation, 11. Amsterdam: John Benjamins Publishing. http://dx.doi.org/10.1075/btl.11

Vygotsky, L. (1986). Thought and language. Cambridge, MA: The MIT Press.

Waddington, C. (2001). Different methods of evaluating student translations: The question of validity. Meta: Journal des traducteurs Meta: /Translators' Journal, 46(2), 311-332. http://dx.doi.org/10.7202/004583ar

Wertsch, J. V. (1991). Voices of the mind: A sociocultural approach to mediated action. Cambridge, MA: Harvard University Press.

Wertsch, J. V. (1998). Mind as action. New York: Oxford University Press.

Wistner, B., \& Sakai, H. (2008). Rasch analysis of English language placement tests. In K. B. Watts, T. Muller, \& M. Swanson (Eds.), JALT 2007 conference proceedings. Tokyo: JALT.

Yarahmadzehi, N., Beikian, A., \& Nadri, F. (2013).A study of Persian translations of English phrasal verbs in Harry Potter and the Order of the Phoenix. International Journal of English Linguistics, 3(1), 60-66. http://dx.doi.org/10.5539/ijel.v3n1p60

\section{Copyrights}

Copyright for this article is retained by the author(s), with first publication rights granted to the journal.

This is an open-access article distributed under the terms and conditions of the Creative Commons Attribution license (http://creativecommons.org/licenses/by/4.0/). 